\title{
Calculation the Effect of Nominal Limit to the Need for Additional Facilities and Paramedics with the System Dynamics Methodology
}

\author{
Aries Susanty, Nia Budi Puspitasari \\ Department of Industrial Engineering \\ Faculty of Technique, Diponegoro University \\ Semarang, Indonesia \\ ariessusanty@gmail.com
}

\author{
Purnawan Adi Wicaksono, Diva Permatasari \\ Department of Industrial Engineering \\ Faculty of Technique, Diponegoro University \\ Semarang, Indonesia \\ diva.rachmadina@gmail.com
}

\begin{abstract}
There are some problems faced by the Healthcare and Social Security Agency (Badan Penyelenggara Jaminan Sosial Kesehatan or "BPJS Health") in managing communitybased health insurance program. In fact, the number of patients has increased dramatically and this condition influences the available capacity of the bed in the public health care center (Pusat Kesehatan Masyarakat or Puskemas) and hospital, and the available capacity of the paramedics. In the end, this condition will affect the total cost to be covered by the by BPJS Health and also influences the degree of satisfaction of the participant of this program. Based on this condition, this study will give BPJS Health a suggestion to switch the current system with the indemnity insurance payment system. Indemnity plans referred to as "fee-for-service" plans which have a nominal limit restricted the cost of health care of each participant. Then, according to a nominal limit, this study want to develop the simulation that describes the interrelationships between the nominal limit and the various factors that affect the availability of facilities and paramedics needed (such as number of number of beds in hospital, number of physicians, specialist, and nurses). This simulation will be carried out by the system dynamics methodology. The result of the simulation showed that, when BJS Health set the nominal limits, the number of participants of BPJS health will decrease slightly compared to the current state. Based on this condition, the demand of bed of the hospital, the demand of physicians, specialist, and nurses will also decrease slightly compared to the current state. For the next year, if the nominal limit is assigned, 49 additional hospital beds, 11.694 additional physicians, and $\mathbf{1 4 . 5 6 6}$ additional nurses would be required for the Province of Central of Java. In the others hand, if the nominal limit didn't assigned, for the next year, 966 additional hospital beds, 12.645 additional physicians, and $\mathbf{1 7 . 3 6 4}$ additional nurses would be required for the Province of Central of Java.
\end{abstract}

Keywords- health care and social security agency; BPJS health, nominal limit; simulation; system dynamics methodology

\section{INTRODUCTION}

Health financing through general taxation or through social health insurance are commonly recognized to be powerful methods to reach universal coverage with adequate financial protection for all against health care costs. In tax funded systems, the population give a contribution indirectly via taxes, whereas in Social Health Insurance (SHI) systems, workers and enterprises generally pay in via contributions based on salaries. Both of system is not easy to achieve in many developing countries, especially for the low-income countries. It is because health systems that depend upon a share of government tax revenue have been generally constrained by insufficient levels of government revenue. This condition implies that only a part of the population can be reached and that, if it is reached, the amount of health service benefits offered is generally insufficient. SHI systems may be particularly difficult to arrive at a nationwide consensus between various partners to agree the basic rule of SHI, such as to stay, guaranteeing similar health service benefits to those with similar health care needs, regardless of the level of contributions that were made. This problem may be very acute when countries show to have a significant inequality of incomes and assets, and where middle and high income earners would be hesitant to contribute significantly more than the poor [1]

Related with social health insurance, Indonesia have had consolidated National Health Insurance (or Jaminan Kesehatan Nasional or JKN) since 1 January 2014. There were many steps is taken during the years between passage of Law 40 in 2004 until the launch of the consolidated National Health Insurance Scheme on 1 January 2014. All of this step aims to fulfillment of the national commitment to have a health care system for all Indonesians. When the law was implemented in 2004, health insurance was only covering civil servants, the military, and the police; each in a separate program. Consideration was first focused to develop new coverage for the health needs of the poor. In 2005, a new Social Health Insurance for the Poor program was launched for that purpose; this new social health insurance is called Asuransi Kesehatan untuk yang Miskin or Askeskin. Three years later, Askeskin evolved into a broader program of health insurance (known as Jamkesmas) with wider coverage and incorporating lessons learned from Askeskin. In 2010, a new program was added to reduce maternal and child mortality, providing coverage for all pregnant women (Jaminan Persalinan or Jampersal). The final years of preparation for the launch of JKN focused on designing how to consolidate the multiple programs under one national administrative, management, and service system while at the same time identifying and moving to "fill gaps" in coverage (improving equity) and raising the quality of services. This period included the development of a "road map" for continuing expansion of the system since its launch in 2014 to the achievement of Universal Health Care or UHC by 2019. After 
the establishment of JKN on 1 January 2014, all health insurance programs implemented by the government that covered the poor and near poor (recipients of government fee support or Penerima Bantuan Iuran or PBI), civil servants, the military, the police, pensioners, and some staff of state-owned and private companies brought together under consolidated National Health Insurance organized by the Healthcare and Social Security Agency (or Badan Penyelenggara Jaminan Sosial Kesehatan or BPJS Health) [2],[3],[4]. BPJS Health is a non-profit public entity that is directly responsible to the President of Indonesia [5].

There is some problem faced by BPJS Health since this program starts its operation in 2014, such as limited capacity of hospitals, limited budget, complaints from an employee of the hospital, and the degree of satisfaction of the participant of this program. The requirement for hospital increase significantly as BPJS Health starts its operation. In this case, 121 million people are projected to be able to enjoy the service of BPJS Health. The number might symbolize a big figure, but it is still far away from the official target of BPJS Health to cover every Indonesian citizen, approximately 250 million people by 2017 [6]. According to one state hospital in the outskirts of Jakarta, since BPJS Health starts its operation in 2014, the hospital gets on average 1,000 patients a day, and 800 of those are BPJS patients. The surge in the number of patients has not been coupled with the addition of hospital workers or significant salary increase for existing employees, which has resulted in a lot of complaints from an employee of the hospital [7]. The increasing number of patients that come to the hospital also influence the amount of total cost to be covered by the by BPJS Health and the degree of satisfaction of the participant of this program. The amount of the total cost to be covered by BPJS is a serious problem because the only source of funding for this program is the national budget which serves as a subsidy for the poor and the near poor. For 2014, the government allocated nearly IDR 20 trillion (US\$ 1.6 billion) to cover premiums for the poor, which accounts for a contribution of IDR 19,225 (US\$ 1.57) per person per month. It is barely enough to buy insurance for third-class $[7\rceil$. Based on this condition, this study will give BPJS Health a suggestion to switch the current system with the indemnity insurance payment system. Indemnity plans are referred to as "fee-for-service" plans which have a nominal limit restricted the cost of health care of each participant. Then, according to an effect of the nominal limit to the health care system, this study want to develop the simulation that describes the interrelationships between the various variable that affect the availability of facilities and paramedics needed (such as bed in Puskesmas or public health care center and hospital, physicians, specialist, and nurses). Based on an understanding of this relation, this study tries to calculate the amount of facilities and paramedics needed before and after BPJS Health introduce a nominal limit. It is necessary to use the system dynamics approach in this study since the system dynamics approach has the advantage to help researchers understand more about the complex system in health care.

The remainder of this paper is organized as follows. Section 2 presents the illustration about system dynamics and use of system dynamic in the health care. Section 3 introduces the research methodology that contains a data collection, causal loop diagram, and stock and flow diagram. Section 4 presents the research results obtained from simulation of two scenarios; followed by managerial implications. Finally, we conclude this paper with our research process findings, the limitation of study and suggestions for future study

\section{LITERATURE REVIEW}

A system is defined as a complex set of interacting elements. The notion of system underlies the concept of totality, according to which "the whole is greater than the sum of the parts" [8]. A system is said to be complex due to the multiplicity of its elements (natural, technical, economic and social) and of their interactions, but also because of the diversity of behaviors and properties it can exhibit (dynamic, emergent, etc.). A complex system is dynamic when characterized by: (1) strong interactions between the various actors of the system; (2) a strong dependency on time; (3) an internal complex causal structure subjected to feedbacks; and (4) delayed behavioral reactions, which are counterintuitive and difficult to predict [9]

System dynamics help individuals to understand the dynamic behavior of complex systems. This method was developed by Forrester (1961) [10]. The basic principle underlying system dynamics is that the structure of a system determines its behavior over time [9], [10]. System dynamics tools will give a greater understanding of the problems being investigated, thereby enhancing managers' abilities to make informed decisions. System dynamics use two structural ways to analyze any dynamic systems: 'causal loop diagram' and 'stock and flow diagram'. Causal Loop Diagram is a graphical representation and it can be used to show the governing interrelations among a number of different variable using feedback loops. There are positive and negative feedback loops. A positive feedback loop means the dependent variable moves in the same direction as that of the independent variable; as such, the polarities are assigned as a plus (+) sign on the arrowhead of feedback loops. In the case of negative feedback loops, if the independent variable increases, the dependent variable decreases and vice versa. Thus a minus (-) sign is assigned to the arrowhead of the feedback loop. The major feedback mechanisms of a model are captured by causal diagrams [11], [12], [13]. The second structure of system dynamics is a stock and flow diagram. This diagram is used to explain both variables, i.e. the stocks and flows. Stocks refer to the status of variables at a point/moment of time while flows exist during a period of time. Stocks are accumulated over time through inflows and outflows. Apart from stock and flow variables, another kind of variable called an 'auxiliary variable' has been used here. Auxiliary variables are used to connect between stocks and flows as well as among themselves. By using all these three kinds of variables, we can explain dynamic systems more appropriately. Many researchers and authors have used stock and flow diagrams to model and describe supply chain performance variables [13], [14], [15].

System dynamics has a long history investigating complex problems in a variety of application areas, ranging from environmental or public policy, corporate strategy, security, healthcare, and operations management, to change management [16]. Reference [17] and [18] contend that since 
the 1970's, system dynamics is used by innovative researchers for simulation modeling techniques to better understand some of the toughest problems that health care managers face. Research shows that some of these problems are intractable to comprehend using conventional epidemiological research methods [9]. System dynamics has become a popular and effective decision-making tool for health care managers because the healthcare system is large and complex; it does not naturally lend itself to easy analysis, design, or even understanding. The complexity and critical nature of the system request for the development and use of good, representative models [19]. There are numerous stakeholders in healthcare. The quantity of the stakeholders is also increasing. This drives complexity in healthcare [20]. The major stakeholders in healthcare include patients, physicians, nurses, hospitals, healthcare organizations, pharmacies, government regulatory groups, licensing and funding agencies, and insurance companies [11], [12]. Some of the applications of System Dynamics modeling in healthcare include; immunization coverage, as in [21]; epidemics, as in [22], [23]; disease management, as in [24], [25]; supply and demand of human resources for health, as in [18]; health planning and chronic illnesses, as in [26]. Reference [27] used simulation and modeling to quantify the effects of different prevention and treatment policies in HIV/AIDS. Reference [28] employed simulation and modeling in the investigation of the effect of time intervals between success cervical cancer screening. Reference [29] used simulation and modeling to study the causes of waiting lists escalation. These studies demonstrate that System Dynamics models can be used to imitate reality, describe the characteristics of a given system and can be employed when the problem under investigation is too complex to be understood

\section{Method OF RESEARCH}

\section{A. Data Collection}

This study utilized both primary and secondary sources of data. The primary sources of data consisting of questionnaires and personal interviews. The questionnaire is open ended questions. In this study, more than one hundred copies of the questionnaire were administered to member of BPJS health located in Jepara, Magelang, and Semarang. The questionnaire designed in this study comprised of two sections. The first part included the demographic and operational characteristics designed to determine the fundamental issues, including the demographic characteristics of the respondent. The second part was devoted to indicate the tendency of respondent to remain as the participant of BPJS Health when the government sets a nominal limit. The second part of the questionnaire also devoted to indicate whether the respondent change of their behavior in visiting the public health care center and hospital after the government set a nominal limit. Then, the interview is carried out to several participants in order to clarify their attitude towards the nominal limit of BPJS Health. The result of questionnaire and interviews are needed to build a scenario which will be simulated. The secondary sources of data consisting of data from BPJS Health and Central Bureau of Statistics of Province of Central of Java, such as data about the number of participants of BPJS Health in Province of Central of Java, the capacity of health facility (number of public health care center, hospital, paramedics), number of claims from participant of BPJS Health, and the other data which is needed to support modelling system with system dynamics

\section{B. Modeling using System Dynamics}

In this study, system dynamics were used to conceptualize and to model the complex of the interrelationships between the nominal limit and others various variable that affect the availability of facilities and paramedics needed (such as bed in hospital, physicians, specialist, and nurses). This study used Powersim software to make simulation. Firstly, this study determined to develop causal loop diagram and then input relevant cause-and effect variables in the stock-flow diagram one by one to develop the system dynamics model. The causal loop diagram and stock-flow diagram of this study are as follows.

\section{Causal Loop Diagram}

A causal loop diagram is shown in Figure 1. This causal loop diagram illustrates how the nominal limit and others various variable influencing the availability of facilities and paramedics needed (such as bed in hospital, physicians, specialist, and nurses) and their interrelationships.

As shown in Figure 1, when the government set a nominal limit for BPJS's participant, the total number of participants of BPJS may be decreased because part of them feel not comfortable with this provision. This condition will have an impact on the number of BPJS's participant outpatient visit the public health care center and hospital. This condition also will have an impact on the total number of BPJS's participant inpatient in the public health care center and hospital. If there is a decrease in the total number of BPJS's participant outpatient visit the public health care center and hospital and the total number of BPJS's participant inpatient in the public health care center and hospital, the need of bed in hospital and the need of paramedics will also be decreased.

Although there is a decrease in the total number participant of BPJS when the government set a nominal limit, demand for health care services and resources are still increasing in line with the addition of a number of patients. Increasing demand for bed space and paramedics, such as physicians, specialist, and nurses will reduce their availability. The gap between their available capacity and demand for bed space and paramedics will create the need for bed space and paramedics in the future. 


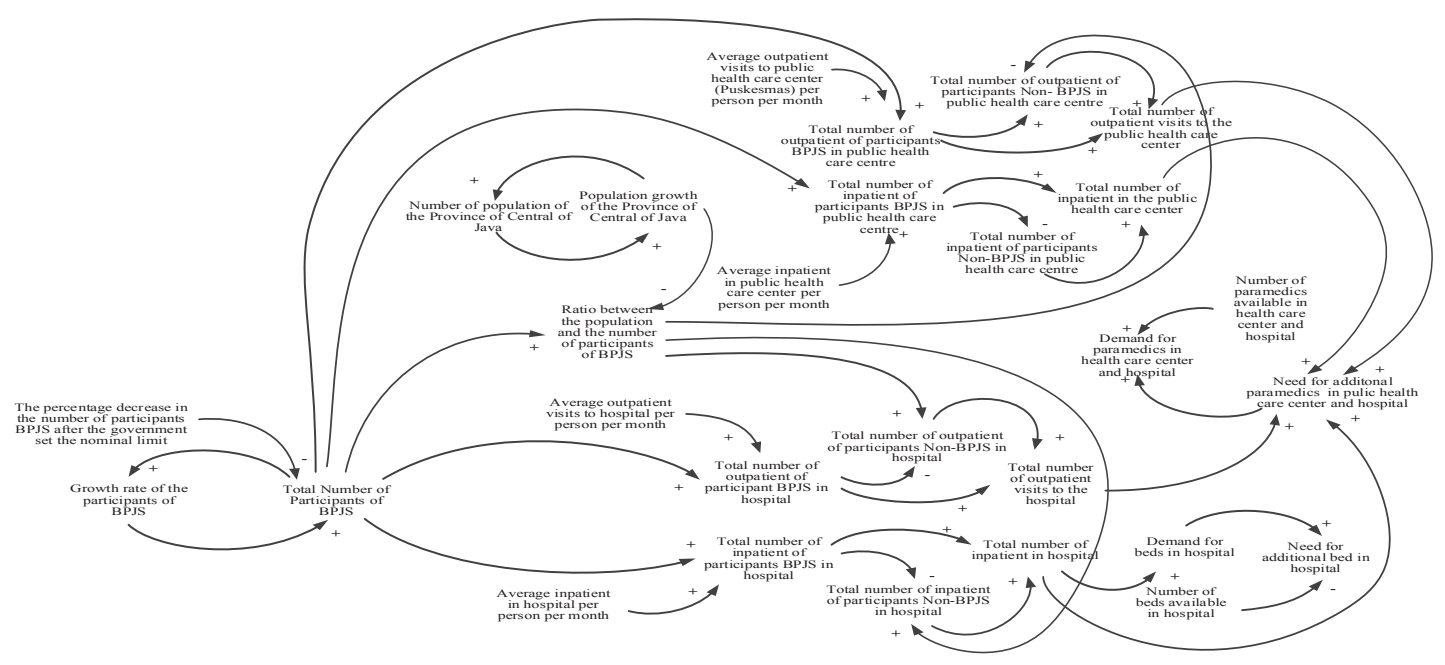

Fig. 1. Causal Loop Diagram

\section{Stock-flow diagram}

A stock-flow diagram for total participant of BPJS health is shown in Figure 2 and its mathematical formula can be seen in Appendix.

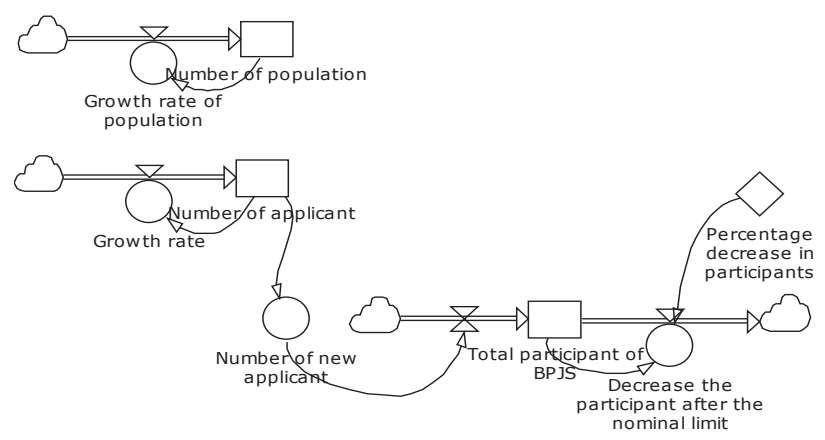

Fig. 2. Stock-flow diagram for total participant of BPJS health

Variable 'decrease the participant after the nominal limit' is the result of multiplying the variable 'total participants BPJS 'with the constantan 'percentage decrease in participant' who will be out of membership BPJS if the policy about the nominal limit is applied. The value for 'total participants BPJS' is referring to the amount of BPJS health in 2014. The value for the constant 'percentage decrease in participant' is obtained from the result of questionnaires which have given to 150 participants, which belongs to non-recipients of government fee support. Of the 150 participants, only 1 participant stated that he would be out of membership BPJS when the government set a nominal limit. It is equal to 0.0066 or $0.67 \%$.

Stock and flow diagram that illustrate the need for additional hospital bed and paramedics can be seen in Figure 3 and its mathematical formula can be seen in the Appendix. The value of 'average outpatient visits to a public health care center per person per month' is resulted from the division between the total numbers of outpatient in the public health care center in the Province of Central of Java in one month with a number of population. So, constant value of 0.10023 means average outpatient visits per persons is 0.10023 times in one month. Thus, the variable 'average inpatient in the public health care center per person per month' is resulted from the division between the total numbers of inpatient in the public health care centers in the Province of Central of Java in one month with a number of population. So, the constant value of 0.00135 means average inpatient per person is 0.0035 times in one month. In the same way, the value of 'average outpatient visits to hospital per person per month' and average inpatient in hospital per person per month' is obtained.

The amount of outpatient without BPJS in the public health care center is obtained by adding the two ratio times 'Total number of outpatients of participants BPJS'. The first ratio is the proportion between the number of outpatients without BPJS and outpatient with BPJS in several public health care centers in the Province of Central of Java. This ratio has resulted from secondary data from 4 public health care center in Central of Java (public health care center in Srondol, Padagsari, Kekopan, and Jurangombo). According to the secondary data from 4 public health care center in Central of Java, in one month, the average proportion of outpatient with BPJS is 1.077204 times the outpatient with BPJS. Then, the second ratio is the proportion between the numbers of patients without BPJS against the patient with BPJS. The amount of inpatient without BPJS in the public health care center is also obtained by adding the two ratio times 'Total number of inpatient of participants BPJS in the public health care center'. The first ratio is the proportion between the number of inpatient without BPJS and with BPJS in several public health care centers in the Province of Central of Java. The second ratio is the proportion between the numbers of patients without BPJS against the patient with BPJS. However, in this simulation model, the value for 'total number of inpatient of participants Non-BPJS in public health care center' equal to 0 . It is because, until now, there is no participant outside BPJS become inpatient in the public health care center. In the same way, the amount of outpatient without BPJS in the hospital and the amount of inpatient without BPJS in the public health care center are obtained. 


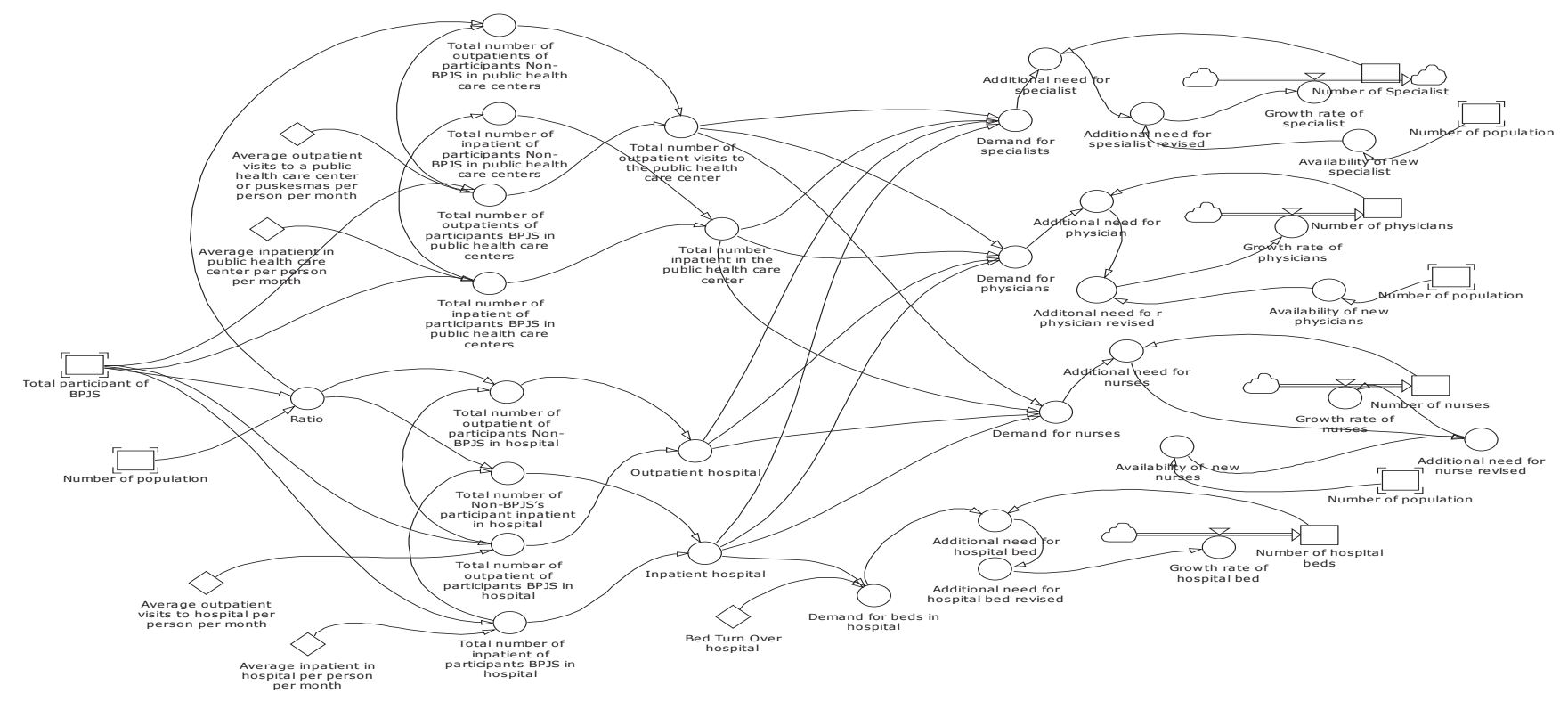

Fig. 3. Stock-flow diagram for the need of additonal hospital bed and paramedics

The need for additional bed is resulted from the gap between demands for bed space and number of beds currently available. Demands of bed space have resulted from the division between total number of patients (inpatient and outpatient) and bed turnover. Bed turnover rate is the number of times patients use hospital beds during a given period of time. It shows the number of times a bed is occupied or vacant during a specific time period and indicates the average number of patients who use a specific bed during a given time interval [30]. Bed turnover is a division between the number of patients (dead or alive) divided by the number of beds. According to Information Management System Organization of Province of Central of Java, the bed turnover rate for the hospital is 5 (http://organisasi.jatengprov.go.id/). Then, the additional of the bed of the hospital is needed when the demands of bed space more than the number of beds currently available, otherwise the additional bed isn't needed. Nevertheless, the additional need for the bed space is limited by the prevalence of the additional of the bed of the hospital in one month.

The need for additional physicians, specialist, and nurses is resulted from the gap between demands for physicians, specialist, and nurses and the number of physicians, specialist, and nurses currently available. Demands of physicians, specialist, and nurses have resulted from dividing between the total number of patients (inpatient and outpatient) and the specific of amount of physicians, specialist, and nurses which has been established by regulation from the Ministry of Health Republic Indonesia. There should be 40 physicians, 6 specialists, and 40 nurses for every 100.000 population. These numbers are then converted into the number of patients can be served by one paramedic. So, after being converted, there should be 1 physicians for every 335 population, 1 specialist for every 2.228 population, and 1 nurse for every 114 population. The additional capacity of physicians is needed when the demands for physicians more than the number of physicians, specialist, and nurses currently available; otherwise the additional physicians isn't needed. Nevertheless, the additional need of physicians is limited by the budget owned by government. According to the Strategic Plan of the government of the Province of Central of Java, for 2013 until 2019, they have set a budget for the addition of physicians as much as 0.1 per 100.000 population, specialist 0.01 per 100.000 population, and nurses 0.5 per 100.000 population (please see the equation). In the same way, the additional need for specialist and nurses can be calculated.

\section{Model Validation}

Model validation is an important aspect of any modelbased methodology in general, and systems dynamics in particular. The validity of the results that given by this study are crucially dependent on the validity of the model. Model validation may be defined as establishing confidence in the usefulness of a model with respect to its purpose [31]. There are two types of model validity used in this study, conceptual and operational validity. Conceptual validity used face validity technique. In this his technique, we ask the person's knowledge (experts) about the system, whether the model and its behavior are realistic. In this case, from the conceptual model, several experts in the field of health have given suggestion that the conceptual model accordance with the substances this research. Then, operational validity used Wilcoxon-rank test. In statistical perspective. The Wilcoxon statistics are usually taught as nonparametric alternatives for the 1- and 2-sample Student-t statistics in situations where the data appear to arise from non-normal distributions, or where sample sizes are so small that we cannot check whether they do [32]. Validation with the Wilcoxon-rank test is performed by the number of visits of patient of BPJS in Central of Java 
between the actual with the result of the simulation. Validation with the Wilcoxon-rank test is done by Statistical Package for the Social Science or SPSS and the result can be seen in the following table

TABLE I. RESULT OF VALIDATION THE MODEL WITH WILCOXON-RANK TEST RANKS

\begin{tabular}{|l|l|c|c|c|}
\hline \multicolumn{2}{|c|}{} & N & Mean Rank & Sum of Ranks \\
\hline $\begin{array}{l}\text { Actual- Result } \\
\text { of Simulation }\end{array}$ & $\begin{array}{l}\text { Negative } \\
\text { Ranks }\end{array}$ & 5 & 7,00 & 35,00 \\
\cline { 2 - 5 } & $\begin{array}{l}\text { Positive } \\
\text { Ranks }\end{array}$ & 7 & 6,14 & 43,00 \\
\cline { 2 - 5 } & Ties & 0 & & \\
\cline { 2 - 5 } & Total & 12 & & \\
\hline
\end{tabular}

\begin{tabular}{|c|c|} 
Test Statistics \\
\hline \multicolumn{2}{|c|}{ Actual - Simulation } \\
\hline$Z$ & $-0,314$ \\
\hline Asymp. Sig. (2-tailed) & $\mathbf{0 , 7 5 4}$ \\
\hline
\end{tabular}

According to the result from SPSS, there is no significant difference between the actual number of visits of patient of BPJS and the result of a simulation (sig. $>0.05$ ). So, the model is valid.

\section{DISCUSSION}

There are two scenarios applied to this study. In the first scenario, there is no nominal limit of benefit that can be obtained by the participant of BPJS health. In the second scenario, government sets a nominal limit of benefit that can be obtained by the participant of BPJS health. As the result of a simulation can be seen, although the government sets a nominal limit of benefit, the number of participants of BPJS health is still increasing. It is mainly because the proportion of participant who refuse to become a member of BPJS health after the government set the nominal limit of benefit is very small. There are only $0.67 \%$ or only 1 of 150 participant refuse to join the BPJS health when the government sets a nominal limit of benefit.

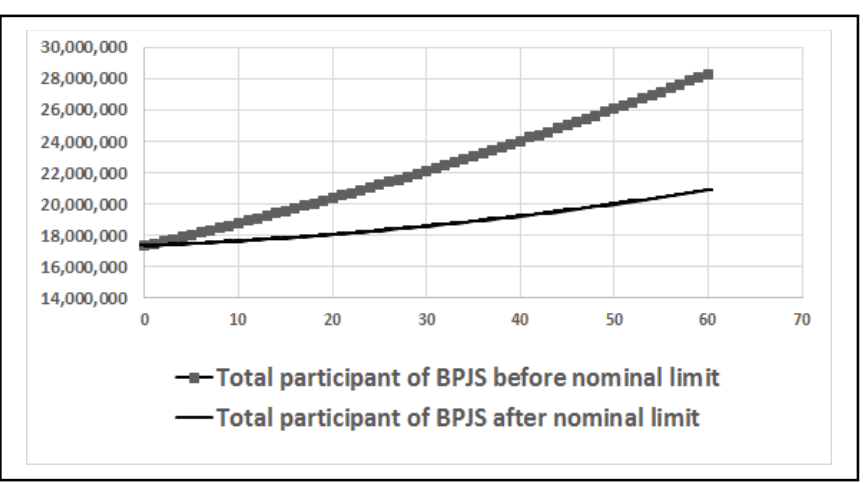

Fig. 4. Result of simulation of total participant of BPJS before and after the nominal limit enforced

Nevertheless, an increasing number of participants of BPJS health after the government set a nominal limit of benefit is lower than the current state. An increasing number of participants of BPJS after the government set a nominal limit slighter than the existing condition. This trend will be kept in

the future 5 years (60 month). After 5 years, the gap between the number of participants of BPJS health before and after the government set a nominal limit is widening. This condition will ultimately impact the demand for bed of hospital, physician, specialist, and nurses. The comparisons between the demands of bed of hospital, physician, specialist, and nurses before and after a nominal limit enforced can be seen in Figure 5 until Figure 8.

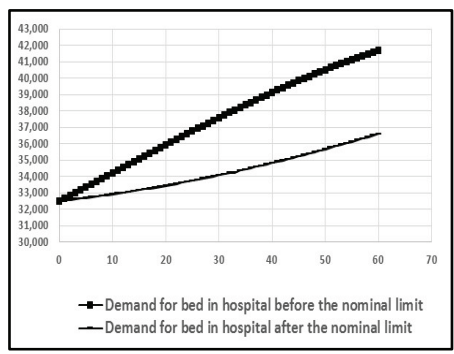

Fig. 5. Demand for hospital bed before and after the nominal limit enforced

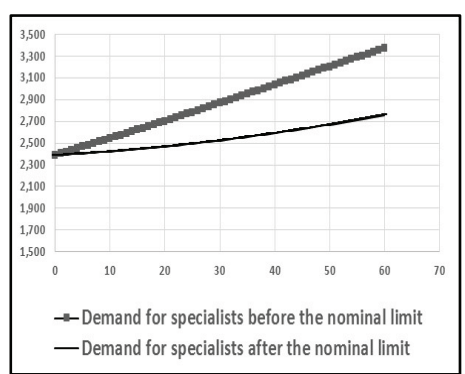

Fig. 7. The demand for specialist before and after the nominal limit enforced

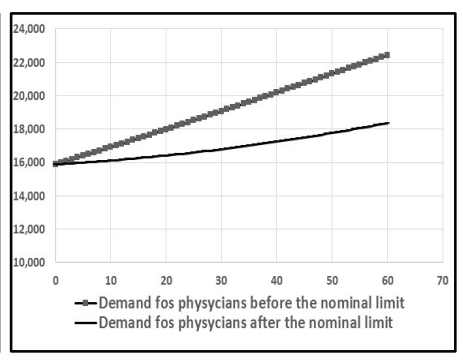

Fig. 6. Demand for physician before and after the nominal limit enforced

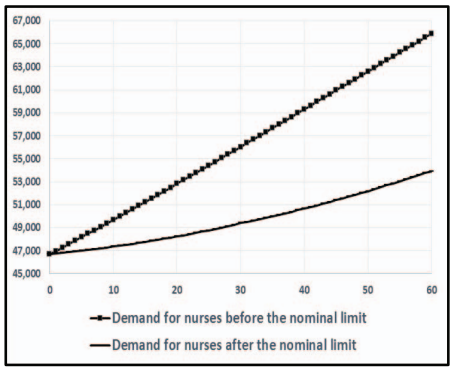

Fig. 8. The demand for nurses before and after the nominal limit enforced

According to the result of simulation, for the next year, if the nominal limit is assigned, 49 additional hospital beds, 11.694 additional physicians, and 14.566 additional nurses would be required for the Province of Central of Java. In the other hand, if the nominal limit didn't assign, for the next year, 966 additional hospital beds, 12.645 additional physicians, and 17.364 additional nurses would be required for the Province of Central of Java. It is not necessary to add the specialist before and after the nominal limit assigned because the number of specialists in the Central of Java is sufficient to meet demand. In detail, the need for additional hospital bed, physicians, and nurses before and after the nominal limit can be seen in Figure 9 until Figure 11.

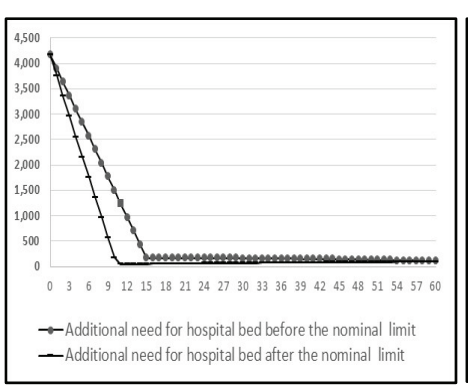

Fig. 9. Need for additional hospital bed before and after the nominal

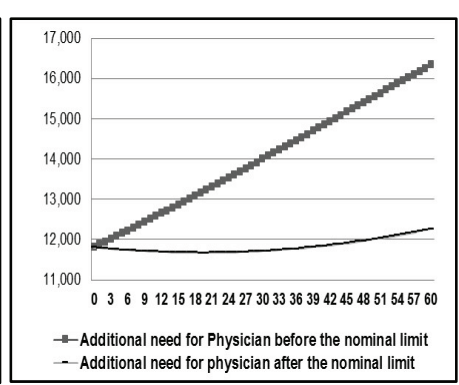

Fig. 10. Need for additional physician before and after the 


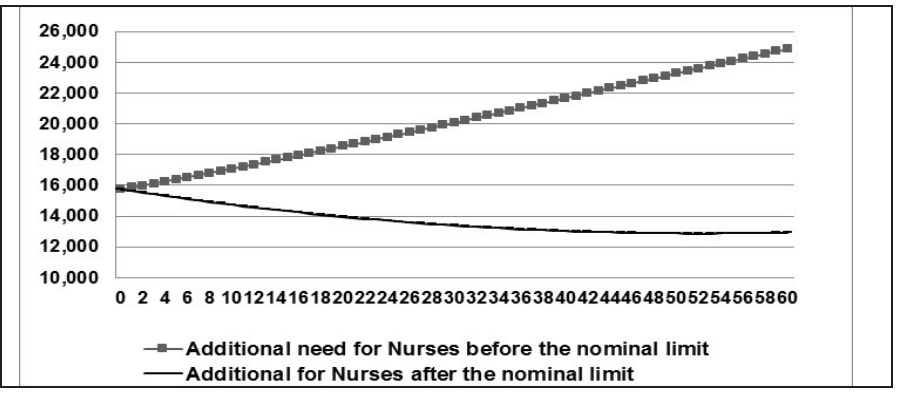

Fig. 11. Need for additional nurses before and after the nominal limit enforced

\section{CONCLUSION, LIMITATION OF STUDY, AND FUTURE RESEARCH}

This paper builds a system dynamics model to describe interrelationships between the nominal limit and the various factors that affect the availability of facilities and paramedics needed (such as the number of hospital beds, number of physicians, specialist, and nurses). At the meantime, the paper predicts the need of hospital beds, physicians, and nurses in the future 5 years ( 60 months) before and after the nominal limit assigned. It shows that the need of hospital beds, physicians, and nurses will continue to increase and the number of population and the number of participants of BPJS health still the important driving factors. Even going increase, the result of the simulation showed that, when the government set a nominal limit of benefit to participants of BJS Health, the number of participants will decrease slightly compared to the current state. Based on this condition, the demand of hospital bed, the demand of physicians, specialist, and nurses will also decrease slightly compared to the current state. For the next year, if the nominal limit is assigned, 49 additional hospital beds, 11.694 additional physicians, and 14.566 additional nurses would be required for the Province of Central of Java. In the other hand, if the nominal limit didn't assign, for the next year, 966 additional hospital beds, 12.645 additional physicians, and 17.364 additional nurses would be required for the Province of Central of Java

This study has a few areas of limitations. First of all, this study was not designed to consider the different representative type of bed of hospitals in Central of Java due to time and resource constraints in addition to the limited of the complexity of this study. This study also was not designed to consider the different representative type of specialist. Another limitation of this study is the use of convenience sampling, which can bias the results; however, it is still used in research because of its ability to yield useful information. This study has used the convenience sampling for determining the tendency of BPJS health participant switching to another type of insurance if the government set a nominal limit of benefit. The sample of participant used in this study also limited. The sample of participant of this study only limited to 150 people and didn't adequately represent the all types of participants of BPJS health which belongs to non-recipients of government fee support (i.e. civil servants, the military, the police, pensioners, and staff of state-owned and private companies).
All of the limitations of this study may be a record for future research. Besides that, for future research, this study can designed to consider the difference of each of participant of BPJS health achieve a nominal limit of benefit which was not always be the same for each person. So, the dynamic of the need of additional of hospital bed, physician, specialist, and nurse will be more visible.

\section{ACKNOWLEDGMENT}

This research was financed by the Diponegoro University through Hibah Fundamental

\section{REFERENCES}

[1] G. Carrin, "Community based health insurance schemes in developing countries: facts, problems and perspectives," Discussion Paper, vol.1, pp.1-39, 2003.

[2] X. Bi. A. Tandon. C. Cashin. P. Harimurti. F. Pambudi. and L. John, "Fiscal space for universal health coverage in Indonesia: lessons from Jamkesmas financing," East Asia and Pacific health matters, 2014, Washington, DC: World Bank Group.http://documents.worldbank.org/ curated/en/2014/03/20196736/fiscal-space-universal-health-coverageindonesia-lessons-jamkesmas-financing

[3] P. Marzoeki, A. Tandon, X. Bi, and E. S. Pambudi, E. S. "Universal health coverage for inclusive and sustainable development: country summary report for Indonesia," World Bank Group, Washington, DC: World Bank. https://openknowledge.worldbank.org/handle/10986/20726 License: CC BY 3.0 IGO, 2014

[4] N. Mboi, "Indonesia: on the way to universal health care," Health Systems \& Reform, vol.1, no. 2, pp. 91-97, 2015

[5] L. Trisnantoro, T. Marthias, and D. Harbianto, "Universal health coverage assessment Indonesia,” Report for Global Network for Health Equity (GNHE), 2014

[6] Super Administrator. "Competition in health care industry: bringing Indonesia's health care industry to the next level," World Marketing Community, ttp://www.worldmarketingcommunity.org/content/article/ marketing-events/competition-in-health-care-industry-bringingindonesias-health-care-industry-to-the-next-level\#, 2014.

[7] A. Wirdana, "Inadequate funding may hamper Indonesia health insurance system," The Establishment Pos, http://www.establish mentpost.com/indonesia-health-insurance-inadequate-funding/\#ixzz3iy mNI7vQ , 2014

[8] L. von Bertalanffy, General System Theory - Foundations, Development, Applications. New York: George Braziller, 1968

[9] J. Sterman, Business Dynamics: System Thinking and Modeling for a Complex World. Boston: McGraw- Hill, 2000

[10] J. W. Forrester, Industrial Dynamics. Cambridge, MA: MIT Press, 1961

[11] M. Faezipour, and S. Ferreira, "Applying systems thinking to assess sustainability in healthcare system of systems," International Journal System of Systems Engineering, vol. 2, no. 4, pp. 290-308, 2011

[12] M. Faezipoura, and S. Ferreiraa, "A system dynamics perspective of patient satisfaction in healthcare," Procedia Computer Science, vol.16, pp. $148-156,2013$

[13] Asgari and M. A. Hoque, "A system dynamics approach to aupply chain performance analysis of the ready-made-garment industry in Bangladesh," Ritsumeikan Journal of Asia Pacific Studies, vol. 32, pp. 51-61, 2013

[14] A. Agarwal, and R. Shankar, R.. "Modeling supply chain performance variables," Asian Academy of Management Journal, vol. 1, no. 2, pp. 47-68, 2005.

[15] F. Campuzano, and J. Mula, "Supply chain simulation: A system dynamics approach for improving performance," London: Springer, 2011

[16] G. P. Richardson, and P. Otto, "Applications of system dynamics in marketing: editorial," Journal of Business Research, vol.61, no. 11, pp. 1099-1101, 2009 
[17] D. Fone, S. Hollinghurst, M. Tempe, A Round, N. Lester, A. Weightman, K. Roberts, E. Coyle, G. Beaven, and S. Palmer, "Systematic review of the use and value of computer simulation modeling in population health and health care delivery," Journal of Public Health Medicine, vol.25, no.4, pp. 325-335, 2003

[18] M. Logan, A simulation model of the system of health care in the united states, Master's Thesis, George Mason University Graduate Nursing Programs, 1998

[19] P. Koelling, and M. J. Schwandt, "Health systems: a dynamic system benefits from system dynamics,' in Proceedings of the $37^{\text {th }}$ Winter Simulation Conference, M. E. Kuhl, N. M. Steiger, F. B. Armstrong, and J. A. Joines, Eds. Florida, 2005

[20] G. Baxter, "White paper: complexity in health care, " Large Scale Complex IT Systems (LSCITS), The UK National Research and Training Initiative, 2010

[21] A. Rwashana, and D. Williams, "Enhancing immunisation coverage through health information systems: a system dynamics approach," Studies in Health Technology Informatics, vol.130, pp. 247-256, 2007

[22] B. Eskici, and B.Turkgulu, "Modeling the dynamics of avian influenza epidemics and possible pandemics" in Proceeding of the 25th International Conference of the System Dynamics Society and 50th Anniversary Celebration, 2007.

[23] M. Ewers, and L. Dauelsberg, "Pandemic influenza mitigation strategies and their economic impacts," in Proceeding of the 25th International Conference of the System Dynamics Society and 50th Anniversary Celebration, 2007

[24] A. Mashayekhi, and P. Boggs, "A system dynamics model of asthma care," in Proceeding of the 25th International Conference of the System Dynamics Society and 50th Anniversary Celebration, 2007

[25] K. Wahba, "Leukemia dynamics: the role of the immune system against Chronic Myelogenous Leukemia (CML)," in Proceeding of the 25th
International Conference of the System Dynamics Society and 50th Anniversary Celebration, 2007

[26] D. Lynell and G. McDonnell, "A dynamic balanced scorecard for managing health systems performance," in Proceeding of the 25th International Conference of the System Dynamics Society and 50th Anniversary Celebration, 2007

[27] B. Dangerfield, F. Fong, and C. Roberts,. "Model based scenarios for the epidemiology of HIV/AIDS: the consequences of highly antiretroviral therap," System Dynamics Review, vol. 17, no.2, pp. 119-150, 2001

[28] G. Royston, A. Dost, J. Townshend, and H. Turner, "Using system dynamics to help develop and implement policies and programmes in health care in England," System Dynamics Review, vol.15, no.3, pp. 293-313, 1999

[29] E. Wolstenholme, "A patient flow perspective of UK health services; exploring the case for new "Intermediate Care" initiatives,' System Dynamics Review, vol.15, no.3, pp. 253-271, 1999

[30] Mohebbifar, R., Sokhanvar, M. Hasanpoor, E. Isfahani, H. M., Ziaiifar, H., Kakemam, E., and Mohseni, M., "A survey on the performance of hospitals of Qazvin Province by the Pabon Lasso Model," International Research Journal of Biological Sciences, vol. 3, no.12, pp.5-9, 2014

[31] Y. Barlas, "Model validation in system dynamics," in System Dynamics: Exploring the Boundaries, Vol. System Dynamics: Methodological and Technical Issues, Proceedings of International System Dynamics Conference, University of Stirling, Scotland, UK, System Dynamics Society, NY, 1-10, 1994

[32] C. Bellera, M. Julien, and J. A. Hanley, "Normal approximations to the distributions of the wilcoxon statistics: accurate to what N? graphical insights," Journal of Statistics Education, vol. 8, no. 2) pp. 1-17, 2010. 
Appendix

MATHEMATICAL Formula FOR TOTAL PARTICIPANT OF BPJS HEALTH

\begin{tabular}{|l|l|l|}
\hline No. & \multicolumn{1}{|c|}{ Variable } & \multicolumn{1}{|c|}{ Formula } \\
\hline 1. & Growth rate & $0.0086^{*}$ 'Number of applicant' \\
\hline 2. & Number of applicant & 140561 \\
\hline 3. & Number of new applicants & 'Number of Applicant' \\
\hline 4. & Total participant of BPJS & 17315454 \\
\hline 5. & The percentage decrease in participant & 0.0066 \\
\hline 6. & Decrease the participant after the nominal limit & $0.0066^{*}$ Total participant of BPJS' \\
\hline 7. & Number of population & 33264339 \\
\hline 8. & Growth rate of the population & $0.00025862^{*}$ Number of population '
\end{tabular}

\section{MATHEMATICAL Formula the NEEd FOR AdDitionAl Hospital BED AND PARAMEdics}

\begin{tabular}{|c|c|c|}
\hline No. & Variable & Formula \\
\hline 1. & $\begin{array}{l}\text { Average outpatient visits to a public health care center or puskesmas per } \\
\text { person per month }\end{array}$ & 0.10023 \\
\hline 2. & Average inpatient in public health care center per person per month & 0.00135 \\
\hline 3. & $\begin{array}{l}\text { Total number of outpatients of participants BPJS in public health care } \\
\text { centers }\end{array}$ & $\begin{array}{l}\text { Total participant of BPJS '* 'Average outpatient visits to public health care } \\
\text { center or puskesmas per person per month ' }\end{array}$ \\
\hline 4. & $\begin{array}{l}\text { Total number of inpatient of participants BPJS in public health care } \\
\text { centers }\end{array}$ & $\begin{array}{l}\text { 'Total participant of BPJS'*' Average inpatient in public health care center per } \\
\text { person per month' }\end{array}$ \\
\hline 5. & Ratio & ('Number of population'- 'Total participant of BPJS ')/'Number of population' \\
\hline 6. & $\begin{array}{l}\text { Total number of outpatients of participants Non-BPJS in public health } \\
\text { care centers }\end{array}$ & $\begin{array}{l}(1.077204+\text { ratio }) * ' \text { Total number of outpatients of participants BPJS in } \\
\text { public health care center' }\end{array}$ \\
\hline 7. & $\begin{array}{l}\text { Total number of inpatient of participants Non-BPJS in public health care } \\
\text { centers }\end{array}$ & 0*'Total number of inpatient of participants BPJS in public health care center' \\
\hline 8. & Total number of outpatient visits to the public health care center & $\begin{array}{l}\text { 'Total number of outpatients of participants BPJS in health care centre'+'Total } \\
\text { number of outpatients of participants Non-BPJS in public health care center' }\end{array}$ \\
\hline 9. & Total number inpatient in the public health care center & $\begin{array}{l}\text { 'Total number of inpatient of participants BPJS in health care centre'+'Total } \\
\text { number of inpatient of participants Non-BPJS in public health care center' }\end{array}$ \\
\hline 10. & Average outpatient visits to hospital per person per month & 0.02568 \\
\hline 11. & Average inpatient in hospital per person per month & 0.00637 \\
\hline 12. & Total number of outpatients of participants BPJS in hospital & $\begin{array}{l}\text { 'Total participant of BPJS'*'Average outpatient visits to hospital per person } \\
\text { per month' }\end{array}$ \\
\hline 13. & Total number of inpatient of participants BPJS in hospital & $\begin{array}{l}\text { 'Total participant of BPJS'*'Average inpatient in hospital per person per } \\
\text { month' }\end{array}$ \\
\hline 14. & Ratio & ('Number of population'- 'Total participant of BPJS ')/'Number of population' \\
\hline 15 & The total number of outpatients of participants Non-BPJS in hospital & $\begin{array}{l}(0.092449+\text { ratio }) * \text { 'Total number of outpatients of participants BPJS in } \\
\text { hospital' }\end{array}$ \\
\hline 16. & Total number of Non-BPJS's participant inpatient in hospital & (rasio-0.0061)* 'Total number of inpatient of participants BPJS in hospital' \\
\hline 17 & Total number of outpatient visits to the hospital & $\begin{array}{l}\text { 'Total number of outpatients of participants BPJS in hospital'+'Total number } \\
\text { of outpatients of participants Non-BPJS in hospital' }\end{array}$ \\
\hline 18. & Total number of inpatient in the hospital & $\begin{array}{l}\text { 'Total number of inpatient of participants BPJS in hospital'+'Total number of } \\
\text { inpatient of participants Non-BPJS in hospital' }\end{array}$ \\
\hline 19. & Bed turnover in hospital & 5 \\
\hline 20. & Number of hospital beds & 28336 \\
\hline 21. & Growth rate of hospital bed & 'Additional need for hospital bed revised' \\
\hline 22. & Demand for beds in hospital & 'Total number of inpatient in the hospital' * 'Bed turnover in hospital' \\
\hline 23. & Additional need for hospital bed & $\begin{array}{l}\text { IF ('Number of beds of hospital'>'Demand for beds in hospital', 0,'Demand for } \\
\text { beds in hospital'-'Number of beds of hospital') }\end{array}$ \\
\hline 24. & Additional need for hospital bed revised & $\begin{array}{l}\text { IF ('Additional need for hospital bed'>439,439,'additional need for hospital } \\
\text { bed') }\end{array}$ \\
\hline 25. & Number of Specialist & 3718 \\
\hline 26. & Growth rate of specialist & 'Additional need for specialist revised' \\
\hline 27. & Demand for specialists & $\begin{array}{l}(1 / 2228) *(' I n p a t i e n t ~ h o s p i t a l '+' \text { 'Outpatient hospital'+'Inpatient care } \\
\text { center'+'Outpatient care center') }\end{array}$ \\
\hline 28. & Additional need for specialist & $\begin{array}{l}\text { IF('Capacity of specialist'>'Demand for specialists',0,'Demand for specialists'- } \\
\text { 'Capacity of }\end{array}$ \\
\hline 29. & Availability of new specialist & $0.01 *($ 'Number of population'/100000) \\
\hline 30. & Additional need for specialist revised & MIN ('Additional need for specialist','Availability of new specialist') \\
\hline 31. & Number of physicians & 4077 \\
\hline 32. & Growth rate of physicians & 'Additional need for physician revised' \\
\hline
\end{tabular}


Joint International Conference on Electric Vehicular Technology and Industrial, Mechanical, Electrical and Chemical Engineering (ICEVT \& IMECE) 2015

\begin{tabular}{|c|l|l|}
\hline No. & \multicolumn{1}{|c|}{ Variable } & \multicolumn{1}{|c|}{ Formula } \\
\hline 33. & Demand for physicians & $\begin{array}{l}(1 / 335) \text { ('Total number of inpatient in the hospital'+ 'Total number of } \\
\text { inpatient in the public health care center'+'Total number of outpatient visits to } \\
\text { the hospital'+'Total number of outpatient visits to a public health care center') }\end{array}$ \\
\hline 34. & Additional need for physician & $\begin{array}{l}\text { IF('Number of physicians'>'Demand for physicians',0,'Demand for } \\
\text { physicians'-'Number of physicians') }\end{array}$ \\
\hline 35. & Availability of new physicians & $0.1^{*}$ ('Number of population'/100000) \\
\hline 36. & Additional need for physician revised & MIN ('Availabilty of new nurses','Additional need for nurses') \\
\hline 37. & Number of nurses & 30.953 \\
\hline 38. & Growth rate of nurses & 'Additional need for nurse revised' \\
\hline 39. & Demand for nurses & $\begin{array}{l}(1 / 114)^{*}(' \text { Inpatient hospital'+'Outpatient hospital'+'Inpatient care } \\
\text { center'+'Outpatient care center') }\end{array}$ \\
\hline 40. & Additional need for nurses & $\begin{array}{l}\text { F('Number of nurses'>'Demand for nurses',0,'Demand for nurses'-'Number of } \\
\text { nurses') }\end{array}$ \\
\hline 41. & Availability of new nurses & $0.5 *($ Number of population'/100000) \\
\hline 42. & Additional need for nurse revised & MIN ('Availability of new nurses','Additional need for nurses') \\
\hline
\end{tabular}

